\title{
IMPLICAÇÕES DOS SISTEMAS DE SEGREGAÇÃO DO MILHO NA LOGÍSTICA DE TRANSPORTE BRASILEIRA: APLICAÇÃO DE UM PROBLEMA DE COMPLEMENTARIEDADE MISTA
}

\author{
Andréa Leda Ramos de Oliveira \\ Universidade Estadual de Campinas \\ andrea.oliveira@fca.unicampr.br \\ José Maria Ferreira Jardim da Silveira \\ Universidade Estadual de Campinas \\ jmsilv@eco.unicampo.br
}

\begin{abstract}
Resumo: O rápido processo de difusão da biotecnologia agrícola ocorre simultaneamente à necessidade de implementação de um aparato regulatório, que pode implicar em custos adicionais ao longo da cadeia agronegócio. O objetivo da pesquisa é analisar o efeito da segregação do milho na logística de transporte e armazenagem do Brasil, especialmente do milho geneticamente modificados (GM), a partir das diretrizes de acordos multilaterais, bem como os desdobramentos na competitividade no mercado internacional. Para incorporar aspectos relacionados à segregação do milho GM, tais como o custo dos testes para identificar os eventos transgênicos e armazenagem segregada, é proposto um modelo de equilíbrio espacial sob a forma de um Problema de Complementaridade Mista (PCM) que se adapta a esta classe de produto. Os resultados demostraram que com um maior número de testes ao longo das rotas logísticas e a demanda por armazenagem segregada, maior é o aumento do custo de transporte. Quanto mais rígido o processo de identificação, maior é o impacto sobre as exportações. Os fluxos intermodais com destino ao mercado internacional foram os mais afetados e as reduções comerciais mais significativas ocorreram nas regiões brasileiras que estão mais distantes dos portos de exportação. A originalidade desta pesquisa é demonstrada pelo uso de um modelo otimização para avaliar como as questões de regulamentação de um segmento, neste caso da biotecnologia, podem interferir em projetos de infraestrutura logística. Este tipo de aplicação é único no Brasil, abrindo oportunidades para trabalhos futuros para examinar a influência de acordos multilaterais nas decisões estratégicas da logística de um país.

Palavras-chave: Logística, Regulação, Modelos de equilíbrio espacial, Transgênicos.
\end{abstract}

Abstract: The aim of the research is to analyze the effects of segregation of corn on the logistics of transport and storage of Brazil and its impacts on competitiveness in the international market, in a context of building new institutions, in this case, from the simulation of resolutions taken by multilateral agreements. The treatment of the proposed problem demands the search for new analytical tools and simulation scenarios. Thus, the proposal is to develop a partial equilibrium model as a Mixed Complementarity Problem (MCP), which aims to provide guidance for the implementation of more effective policies and that give support to new investments in the corn supply chain. As a main conclusion, it is observed that the logistics of transport and storage in Brazil is affected by the requirements of the Cartagena Protocol on Biosafety. Therefore, the more rigid the identification process, the greater the impact on exports. Intermodal flows were the most affected and the significant commercial reductions occurred in the Brazilian regions that are more distant from ports of export, reflecting a significant loss of competitiveness of the corn supply chain. The 
originality of this research is demonstrated by the use of a optimization model to measure how regulatory issues of a segment, in this case biotechnology, directly interfere in infrastructure logistics projects. This type of application is unique in Brazil by opening opportunities for future works to examine the influence of multilateral agreements in the strategic decisions of a country's logistic.

Keywords: Logistics, Regulation, Partial equilibrium models, Transgenic crops. 


\section{INTRODUÇÃO}

Nas últimas duas décadas a agricultura passou a figurar entre os setores econômicos mais estratégicos para a consolidação do programa de estabilização econômica. Considerando-se alguns aspectos do agronegócio, como a elevada participação no Produto Interno Bruto (PIB) em torno de 20\% [13, 17], a importância na pauta de exportações em mais de 41\% [7], a manutenção do saldo positivo da balança comercial e a contribuição para o controle da inflação, evidencia-se a importância da agricultura brasileira para impulsionar o desempenho da economia.

A cadeia produtiva do milho é um dos segmentos que colaboram para posição de destaque do agronegócio brasileiro. O Brasil é o terceiro maior produtor do grão, ficando apenas atrás da China e dos Estados Unidos, e ocupa a segunda posição no ranking mundial de exportação [31].

É importante destacar que a agricultura moderna e a criação do agronegócio são baseadas em gastos de pesquisa, que foram configurando um amplo sistema de inovação. A biotecnologia ocupa papel de destaque no processo de transformação da agricultura, ao permitir a articulação das distintas fontes de inovação em ambientes diversos [27].

Especialmente para o milho, o advento de variedades transgênicas promoveu avanços em ganhos de produtividade. Para safra 2013/14, a previsão é que a área cultivada com milho geneticamente modificado (GM) seja de 12,5 milhões de hectares, o que representa $81 \%$ da área total de milho (15,5 milhões de hectares) [18].

Apesar da alta taxa de adoção de variedades GM de milho, o avanço da biotecnologia se defronta com a proliferação dos sistemas de biossegurança - incluindo mecanismos de comunicação ao consumidor como rotulagem, preservação de identidade, processos de segregação e de rastreabilidade - que acarretam complicações adicionais ao comércio internacional de produtos agrícolas e afetam a cadeia logística, especialmente afetados pela imposição de sistemas de segregação dos produtos GM.

Diferentemente da maioria dos outros métodos de melhoramento genético de plantas, a biotecnologia moderna e as culturas biotecnológicas são estritamente reguladas com vistas as questões de segurança alimentar e ambiental.

A regulamentação acerca dos organismos geneticamente modificados (OGMs) vem sendo, em tese, desenhada à luz das regras da Convenção sobre Diversidade Biológica (CDB) por meio do Protocolo de Cartagena de Biossegurança (PCB). Da tese à prática, há uma distância coberta pela complexidade da formação de protocolos multilaterais em que o consenso é regra. O espaço para a ação coletiva faz com que a constituição do PCB, no que diz respeito a suas disposições específicas acerca dos OGMs, passe por diversos impasses.

Do ponto de vista da logística de movimentação, a segregação implica no aumento dos custos de armazenamento e transporte [25]. O sistema de full segregation para os grãos requer uma maior quantidade de compartimentos nas unidades de armazenamento ou a necessidade de implantação de silos com menor capacidade, de modo a permitir o armazenamento segregado.

Nesse sentido, o objetivo deste artigo é analisar os efeitos da segregação do milho sobre a logística de transporte e armazenamento do Brasil e seus desdobramentos na competitividade no mercado internacional, em um contexto de construção de novas instituições, no caso, a partir da simulação de resoluções tomadas pelo Protocolo de Cartagena de Biossegurança, PCB.

O tratamento do problema proposto demanda a busca de novas ferramentas analíticas e a simulação de cenários. Dessa forma, a proposta é o desenvolvimento de um modelo de equilíbrio parcial na forma de um Problema de Complementaridade Mista (PCM), que visa fornecer uma orientação para a implementação de políticas mais eficazes e que deem suporte à novos investimentos no setor.

Finalmente, na seção 2 é analisado o papel fundamental da regulação na formação dos mercados de produtos biotecnológicos e as implicações do Protocolo de Cartagena (PCB) por 
meio do Artigo 18.2 na logística de transporte e armazenagem do milho no Brasil. A seção 3 apresenta o modelo adotado - Problema de Complementaridade Mista (PCM), para analisar a questão do milho geneticamente modificada (GM) e a construção dos cenários utilizados. A seção 4 apresenta os principais resultados obtidos com implementação do PCM e os impactos da imposição do PCB nos fluxos comerciais brasileiros. Por fim, a seção 5 apresenta as principais conclusões e contribuições da pesquisa.

\section{SISTEMAS DE SEGREGAÇÃO X LOGÍSTICA DE TRANSPORTE}

A produção de milho no Brasil, juntamente com a de soja, contribui aproximadamente com $80 \%$ da produção de grãos no país [8]. Recentemente, as exportações desse cereal vem sendo realizada em quantidades expressivas e contribuindo para maior sustentação dos preços internos do milho. A principal região produtora é o Centro-Oeste, que detêm $42 \%$ da produção nacional.

Mas um contraponto para o Centro-Oeste precisa ser mencionado. O custo de transporte, especialmente no Brasil, onde são precárias as condições de infraestrutura, acaba onerando o bem movimentado com implicações diretas quanto ao custo de produção do milho, quando transportado a longas distâncias. Isto posto, observa-se que os aspectos regulacionais quanto à segregação de carga, através da implementação de sistemas de preservação full segregation, além das implicações quanto a difusão da tecnologia interferem sobremaneira nos custos produtivos e na configuração logística de movimentação do milho.

A obrigatoriedade na implementação de processos que levem a um aumento nos custos fixos, sem conexão direta com o cumprimento dos objetivos do Protocolo de Cartagena (PCB) - especialmente por meio do artigo 18.2, devem ser vistos como um novo componente no processo de criação de barreiras técnicas ao comércio, com efeitos negativos sobre os produtores agrícolas em países exportadores e sobre os consumidores nos países importadores.

Com base nesse princípio, o PCB estabelece no Artigo 18 as exigências e medidas necessárias com relação à manipulação, transporte, embalagens e identificação de todos os carregamentos que contenham ou possam conter OGMs. O propósito dessa análise se restringe aos carregamentos de OVMs-FFPs (organismos vivos modificados destinados ao uso direto como alimento humano ou animal ou para processamento), cujas exigências constam no parágrafo 2.a do Artigo 18 [19]:

\section{Cada Parte tomará medidas para exigir que a documentação que acompanhe:}

(a) os organismos vivos modificados destinados ao uso direto como alimento humano ou animal ou ao beneficiamento identifique claramente que esses "podem conter" organismos vivos modificados e que não estão destinados à introdução intencional no meio ambiente, bem como um ponto de contato para maiores informações. A Conferência das Partes atuando na qualidade de reunião das Partes do presente Protocolo tomará uma decisão sobre as exigências detalhadas para essa finalidade, inclusive especificação sobre sua identidade e qualquer identificador único, no mais tardar dois anos após a entrada em vigor do presente Protocolo.

Após o debate controverso na COP-MOP3, os membros do Protocolo de Cartagena concordaram em considerar duas opções de identificação de carregamentos OGMs. A opção pelo termo "pode conter", para carregamentos em que os eventos não estão exatamente identificados, pode ser facilmente operacionalizada através da inclusão junto ao carregamento de uma lista de eventos prováveis e os impactos nos fluxos comerciais seriam bem reduzidos. Já o termo "contém” exige medidas adicionais, em que a identidade dos OGMs contidos nos carregamentos deve ser determinada por um Sistema de Preservação de Identidade (SPI) baseado em testes, incluindo uma lista de eventos presentes.

A estruturação dos custos para as culturas preservadas difere do mercado de commodities, pois inclui tanto os custos acrescidos da segregação e as despesas mitigar os riscos específicos para os mercados de IP. Os riscos decorrem de um ou mais fatores de fixação de preços (prêmios de preço, qualidade e informação) e dos instrumentos para o 
cumprimento de protocolos internacionais, dentre eles, o Protocolo de Cartagena de Biossegurança [5].

Apesar dos avanços da biotecnologia, aspectos como infraestrutura e transporte continuam a ser um fator limitante para as potencialidades da agricultura moderna [5].

O aproveitamento do potencial de expansão da produção de grãos depende do estabelecimento de um sistema eficiente de transporte. Tal sistema terá de comportar volumes maiores a custos menores, permitindo, assim, que o setor de grãos aumente a sua contribuição no abastecimento interno de alimentos e mantenha sua posição no mercado internacional.

Em geral, países com pequena extensão territorial vocacionam o seu transporte no modal rodoviário, enquanto países com grandes extensões, com exceção do Brasil, priorizam o transporte para os modais ferroviário e hidroviário, dado que estes modais possuem uma maior eficiência e competitividade no transporte de longas distâncias.

O que é observado na economia agrícola brasileira nas ultimas décadas é a verdadeira revolução em seu arranjo espacial, onde o agronegócio ocupou fronteiras como Norte e Centro-Oeste, e avançando para o Nordeste. Em geral por meio de atividades que incorporam modernas tecnologias de produção. Dessa maneira, introduzindo toda uma cadeia de apoio para o negocio principal, ou seja, fornecedores de insumos, armazenadores e indústrias de processamento se aglomeram ao redor das zonas de produção, com o objetivo de minimizar custos de transporte, e atendendo os princípios de racionalidade econômica [11].

O PCB afetaria com maior intensidade os mercados de soja e milho, produtos com grande participação na produção agrícola mundial. No caso do milho o impacto da segregação da carga para cumprir o PCB é mais intenso, uma vez que o número eventos transgênicos a serem avaliados é superior ao da soja, em média seis. Outro ponto diz respeito à espacialização da produção, a produção de milho é muito mais pulverizada pelo território nacional que a produção de soja, o que dificulta muito o estabelecimento de rotas que permitam calcular o impacto de medidas visando a plena segregação de cargas convencionais versus transgênicas.

O sistema rodoviário brasileiro ainda é o principal modal utilizado para o transporte de cargas agrícolas; em muitos casos, é a única alternativa para movimentação desse tipo de produto, devido à escassez de hidrovias e ferrovias que liguem grandes distâncias e, ao mesmo tempo, situem-se perto dos polos produtores.

O sistema rodoviário brasileiro há muito tempo sofre com a carência de investimentos públicos. Além disso, as empresas de transporte de cargas perderam sua margem de lucro principalmente devido aos produtos de baixa especificidade, o que acarretou deterioramento dos equipamentos e manutenção precária [10].

No modal ferroviário, o uso de vagões inadequados, a pequena oferta de material rodante e a baixa qualidade do existente podem ser considerados as principais deficiências na infraestrutura. Já para o modal hidroviário, o problema reside na baixa capacidade de intermodalidade e comboio, além de oferecer pouca atratividade de investimentos devido às barreiras ambientais.

O transporte hidroviário apresenta vantagens quando comparado aos outros sistemas, principalmente devido ao baixo valor de seu frete. Porém, essa modalidade deve estar conjugada com outras para que os pontos de origem e destino possam ser atendidos. Dessa maneira, as alternativas intermodais devem ser consideradas, apresentando-se como uma maneira mais real de tratar os problemas de transporte de produtos agrícolas [21].

A movimentação de produtos homogêneos e padronizados mostrou-se como uma importante estratégia para garantir ganhos de escala e facilitar a logística. Contudo, nota-se o crescimento da demanda por grãos diferenciados, tais como os grãos com elevados teores de proteína, grãos com rendimento industrial superior, grãos com propriedades nutracêuticas, e ainda, grãos com certificado de produto não geneticamente modificado [6]. 
Nesse contexto, a mudança no sentido do escoamento da produção agrícola decorre de uma redução nos custos de transporte causados pela intermodalidade e a redução da distância até o porto exportador.

Porém, a realidade brasileira não demonstra eficiência no sistema de transporte. A modalidade de transporte rodoviário tem absorvido mais da metade dos transportes de cargas no Brasil [3]. Essa predominância do modal rodoviário pode ser explicada pelas dificuldades que outras modalidades de transporte enfrentam para atender eficientemente aos aumentos de demanda em áreas mais afastadas do País, as quais não são providas de ferrovias ou hidrovias.

\section{METODOLOGIA}

Com vistas a quantificar os impactos potenciais dos custos da implementação do PCB para o Brasil, com foco na organização da logística de transporte e armazenagem brasileira, neste trabalho utiliza-se um modelo de equilíbrio parcial formulado como um Problema de Complementaridade Mista (PCM).

Os modelos de equilíbrio parcial elegem um setor ou produto a ser analisado e examinam os efeitos de uma variação (exógena) do preço relativo sobre o equilíbrio do setor, supondo que a alocação no resto da economia permanece inalterada $[1,12]$.

O uso mais frequente dos modelos de equilíbrio parcial com preços endógenos tem sido observado nos problemas relacionados com a competição de mercados interregionais [33]. Também vêm sendo empregados para simular o impacto de políticas comerciais em diferentes mercados [20]. Além disso, é importante destacar que a estrutura teórica desse modelo pode ser expandida, incluindo regiões multiexportadoras e importadoras, transporte multimodal e multi commodity. E ainda, podem ser utilizados para simular o impacto nos mercados ocorrido por meio da aplicação de políticas de comércio, tais como: quotas, subsídios, tarifas, dentre outros [21].

Como o presente estudo compreende uma análise do impacto do PCB no mercado de milho brasileiro, a abordagem de equilíbrio parcial foi adotada. A escolha desse método proporciona uma avaliação detalhada dos efeitos da implementação do PCB nos fluxos comercias brasileiros, e ainda, possuem a vantagem de permitir a incorporação de tarifas, quotas-tarifárias e subsídios com mais facilidade.

Outra abordagem dos modelos de equilíbrio parcial é o apresentado na forma de um Problema de Complementaridade Mista (PCM). A utilização do PCM foi proposto por [4, 22, 30], e já utilizado por [1, 2].

Um problema de complementaridade consiste em um sistema de equações simultâneas (lineares ou não lineares), que são descritas como desigualdades, a partir das funções de oferta e demanda. O PCM é equivalente às condições de Kuhn-Tucker, que são necessárias e suficientes para atingirem o máximo da função Net Social Payoff ${ }^{1}$ (NSP), que por sua vez, implica conseguir o equilíbrio em todos os mercados e em todas as regiões ${ }^{2}$. Além disso, o PCM tem a vantagem de permitir a incorporação de tarifas, cotas e subsídios com mais facilidade ao modelo [4]. Índices:

O PCM proposto para analisar o mercado de milho brasileiro é apresentado a seguir:

$i=$ regiões de oferta $(i=1, \ldots, 9)$

$j$ = regiões de demanda doméstica $(j=1, \ldots, 3)$

\footnotetext{
${ }^{1}$ A formulação de Samuelson mostra que a maximização da função NSP, dada pela soma dos excedentes dos produtores e consumidores, menos o custo de transporte, e sujeita a equações de balanço regional, gera um quadro de condições de otimalidade, mas vale ressaltar que Samuelson alertou para os problemas associados ao uso de seu modelo para fazer inferências sobre o bem-estar social. Daí a sua expressão "Net Social Payoff", que excluí uma referência ao bem-estar social [24].

${ }^{2}$ Para um problema de programação não-linear em que a função objetivo é diferenciável e côncava, com restrições lineares (diferenciável e convexa), o resultado é o máximo global, uma vez que o ponto ótimo satisfaz as condições de Kuhn-Tucker [28].
} 
$k=$ regiões de demanda internacional $(k=1, \ldots, 3)$

$r$ = rotas de transporte $(r=1, \ldots, 15)$

Variáveis:

$p_{i}=$ preço de oferta

$p_{j}=$ preço de demanda doméstica

$p_{k}=$ preço de demanda internacional

$Z_{i}=$ quantidade ofertada

$y_{j}=$ quantidade consumida pela demanda doméstica

$y_{k}=$ quantidade consumida pela demanda internacional

$x_{x x}=$ quantidade movimentada

Parâmetros

$t_{x x}=$ custo de transporte

$\square_{i}=$ preço - sombra associado à região de oferta $i$

$\square_{j}=$ preço - sombra associado à região de demanda $j$

$\square_{k}=$ preço - sombra associado à região de demanda $k$

$0 \square \square_{i} \square \square_{j}^{J} x_{i j}+\square_{k}^{K} x_{i k} \square z_{i}$

$0 \square \square_{j} \square y_{j} \square \square_{i}^{I} x_{i j}$

$0 \square \square_{k} \square y_{k} \square \bigsqcup_{i}^{I} x_{i k}$

$0 \square x_{i j} \square p_{i}+t_{i j} \square p_{j} \square_{i, j}$

$0 \square x_{i k} \square p_{i}+t_{i k} \square p_{k} \square_{i, k}$

Pelo símbolo " $\square$, entende-se que pelo menos uma das desigualdades adjacentes devem ser satisfeitas como igualdade estrita. Isto nada mais é do que uma formalidade da complementariedade que vimos anteriormente, ao apresentar as condições de Kuhn-Tucker. As equações (4) e (5) estão assim apresentadas para facilitar a inclusão da taxa ou tarifa advalorem acarretada pelo custo do teste para identificação de eventos transgênicos.

A inclusão da tarifa ad-valorem foi baseada no trabalho em [4]. Considerando a condição de lucro zero (5), a inclusão de um parâmetro $\operatorname{tax}_{i k}$, que representa uma taxa ou tarifa ad-valorem, dá-se por uma incorporação no modelo na equação (5). Isso porque, nesse estudo, a taxa tem implicações apenas nos fluxos destinados ao mercado internacional. Modificando a condição de lucro zero, como segue, temos:

$$
\left(p_{i}+t_{i k}\right) \rtimes\left(1+\operatorname{tax}_{i k}\right) \square p_{k} \quad \square_{i, k}
$$

Nesse caso, a taxa é resultante da imposição da realização de testes para identificação e quantificação de eventos OGMs, somados ao custo de armazenagem segregada nos fluxos para o mercado internacional, uma vez que o PCB impõe medidas sobre os movimentos transfronteiriços.

Quando atingido o equilíbrio, na existência de fluxo de comércio entre as regiões produtoras e a demanda internacional, o preço do produto na região de oferta, somado ao custo de transporte, após a imposição dos testes OGM e segregação, deve ser igual ao preço na demanda internacional. Caso contrário, se não houver fluxo comercial, isto significa que o 
preço na região de demanda internacional é menor que o preço na região de oferta somado aos custos de transporte e testes.

No modelo, inicialmente foram identificadas e selecionadas as regiões de oferta e demanda de soja. Os Estados selecionados compõem as regiões Sudeste, Centro-Oeste e Sul. Foi analisado o comportamento dos últimos anos das variáveis: produção de milho; rendimento médio; área cultivada; exportações e consumo de milho na produção suína e avícola. A escolha dos Estados que compuseram o modelo foi baseada na expressividade dessas regiões na participação das variáveis analisadas. O intuito foi caracterizar a dinâmica dessas regiões, que detêm destacada expressão nacional e grande potencialidade de expansão com base nas fronteiras agrícolas.

Os estados selecionados serão: Paraná, Mato Grosso, Mato Grosso do Sul, Góias e Minas Gerais como regiões de oferta de milho, em razão da expressividade na produção e/ou exportação, já São Paulo, Santa Catarina e Rio Grande do Sul como regiões de demanda. Os países importadores de milho considerados são Irã, China e Japão.

Os dados que compõem o modelo (produção, consumo, preços de comercialização do mercado nacional e internacional, elasticidades-preço de oferta e demanda, fretes dos diferentes modais e custos dos testes OVM) tiveram como base o ano de 2011. Os dados de produção tiveram como fonte o Instituto Brasileiro de Geografia e Estatística (IBGE) e o Departamento de Agricultura dos Estados Unidos (USDA). Os dados de consumo tiveram como base a Associação Brasileira de Produtores de Pinto de Corte (APINCO) e Associação Brasileira da Indústria Produtora e Exportadora de Carne Suína (ABIPECS), e as cotações do milho para os mercados nacional e internacional tiveram como base a consultoria Safras \& Mercado (2011) e o USDA (2011), respectivamente. Já os dados de elasticidades-preço de oferta e demanda foram baseados nos estudos desenvolvidos por Fuller et al. (2001 e 2003) e FAPRI (2011). Os fretes dos modais rodoviário, ferroviário, hidroviário e marítimo terão como fonte o Sistema de Informações de Fretes (SIFRECA, 2011).

Com o objetivo de entender os aspectos operacionais da segregação dos grãos OGMs e obter os custos relativos aos testes para identificação de eventos transgênicos e despesas de armazenagem segregada, foram conduzidas entrevistas com os principais agentes do setor (tradings, empresas de transporte e certificadoras). Com base na pesquisa de campo, foram determinados os custos dos testes para identificação de eventos transgênicos, assim como o padrão de amostragem. Existem dois métodos de análise de OGM: um realizado através da análise de DNA e outro, por meio da análise de proteínas. No primeiro caso, a técnica utilizada é o PCR (Polymerase Chain Reaction), de natureza quantitativa ou qualitativa. Já na análise de proteínas, pode-se utilizar o teste ELISA (Enzyme-linked immunosorbent assay) simples ou teste de fita, em que é detectado apenas um evento por vez.

O custo unitário foi de US\$ 3,00 para os testes de fita e de US\$ 300,00 para o PCR. A cada 40 toneladas, são retiradas 2 amostras, o que demanda 2 fitas, dando um custo total de US\$ 6,00. No caso do PCR, foi considerada o PCR Quantitativo Real Time com um custo de US\$ 1.050,00 (U\$/amostra/6eventos), em que faz a realização de 3 análises a cada 3.000 toneladas, perfazendo um total de US\$ 3.150,00, incluindo 1 PCR no momento do embarque, 1 PCR no porto de exportação e 1 PCR no navio.

Os custos de armazenagem segregada foram levantados nas principais companhias exportadoras de milho não-GM. Os custos nos armazéns de transbordo ficaram em torno de US\$13,00/tonelada e a armazenagem nos portos de exportação, em média, US\$10,00/tonelada.

Dessa forma, a estimativa dos custos dos testes e armazenagem foi elaborada com vistas ao uso do termo "contém”, ou seja, que compreende tanto a identificação quanto a quantificação de milho GM. Foram simulados dois cenários distintos. O Cenário 1 foi o de controle, em que não houve despesas com os testes para detecção de OVM e armazenagem segregada, os fluxos comerciais ocorreram somente com base nos custos de transporte, ou seja, sem a imposição do PCB com vistas ao termo "contém”. 
No Cenário 2, foi proposto um quadro de full segregation com vistas ao termo "contém". O teste de PCR foi considerado no momento do embarque, no porto de exportação e no navio. O número de testes de Fita variou de acordo com a rota de transporte considerada. A cada mudança de modal de transporte - o que demanda operações de transbordo, posto que pode ocorrer mistura de carga - foi realizado um teste de fita adicional. A armazenagem segregada também foi considerada ao longo do processo. Com base nessas considerações, a tarifa ad-valorem calculada foi de $60 \%$ nos fluxos intermodais e 55\% nos fluxos unimodais.

O processamento das informações para o PCM desenvolvido para a movimentação de milho no Brasil foi feito utilizando-se o programa computacional General Algebraic Modeling System - GAMS [9].

\section{RESULTADOS E DISCUSSÃO}

Os modelos de programação matemática devem ser validados através da conferência da consistência dos resultados do problema [1]. A validação pressupõe uma adequação dos coeficientes e da estrutura do modelo [32]. O modelo pode ser validado através da verificação de quão bem a solução sugerida pelo modelo se aproxima da situação real. Grande parte dos modelos de equilíbrio espacial não geram resultados idênticos aos dados reais [32].

Dessa forma, algumas diferenças entre os resultados estimados pelo modelo e os dados observados podem ocorrer, sem invalidar o modelo. Na Tabela 1, pode-se verificar os níveis de oferta e demanda estimados pelo modelo. Os volumes praticados em 2011 ("Dados Observados”) e os dados estimados a partir do modelo (“Cenários 1 e 2") também são apresentados.

Tabela 1. Volumes de oferta, demanda doméstica e demanda internacional, estimativas do modelo (cenários 1 e 2) e dados observados, 2011.

\begin{tabular}{|c|c|c|c|c|}
\hline \multirow[t]{2}{*}{ Regiões } & $\begin{array}{l}\text { Cenário } 1 \\
\text { (A) }\end{array}$ & $\begin{array}{l}\text { Cenário } 2 \\
\text { (B) }\end{array}$ & $\begin{array}{c}\text { Dados Observados } \\
\text { (C) }\end{array}$ & $\begin{array}{l}\text { Variação } \\
\text { (B)/(A) }\end{array}$ \\
\hline & \multicolumn{3}{|c|}{ (mil toneladas) } & $(\%)$ \\
\hline \multicolumn{5}{|c|}{ Oferta } \\
\hline Total Mato Grosso & $5.084,25$ & $4.826,21$ & $6.610,10$ & $-5,08$ \\
\hline Norte MT & $3.826,99$ & $3.627,04$ & $4.957,57$ & $-5,22$ \\
\hline Sudeste MT & $1.257,27$ & $1.199,17$ & $1.652,52$ & $-4,62$ \\
\hline Goiás & $3.003,32$ & $2.875,85$ & $4.003,96$ & $-4,24$ \\
\hline Mato Grosso do Sul & $1.962,46$ & $1.848,92$ & $2.747,65$ & $-5,79$ \\
\hline Minas Gerais & $2.704,33$ & $2.610,61$ & $3.385,99$ & $-3,47$ \\
\hline Total Paraná & $4.293,42$ & $4.121,02$ & $5.367,82$ & $-4,02$ \\
\hline Norte PR & $2.840,98$ & $2.677,80$ & $3.489,08$ & $-5,74$ \\
\hline Oeste PR & $1.452,44$ & $1.443,22$ & $1.878,74$ & $-0,64$ \\
\hline OFERTA TOTAL & $17.047,78$ & $16.282,62$ & $22.115,52$ & $-4,49$ \\
\hline \multicolumn{5}{|c|}{ Demanda Doméstica (D) } \\
\hline Santa Catarina & $3.179,39$ & $3.210,72$ & $3.028,19$ & 0,99 \\
\hline Rio Grande do Sul & 130,76 & 130,94 & 124,65 & 0,13 \\
\hline São Paulo & 288,57 & 289,11 & 270,71 & 0,19 \\
\hline Subtotal & $3.598,72$ & $3.630,77$ & $3.423,55$ & 0,89 \\
\hline \multicolumn{5}{|c|}{ Demanda Internacional (E) } \\
\hline Irã & $5.329,65$ & $4.796,90$ & $5.000,00$ & $-10,00$ \\
\hline Japão & $4.016,32$ & $3.983,33$ & $4.000,00$ & $-0,82$ \\
\hline Taiwan & $4.103,10$ & $3.871,61$ & $4.000,00$ & $-5,64$ \\
\hline Subtotal & $13.449,06$ & $12.651,85$ & $13.000,00$ & $-5,93$ \\
\hline DEMANDA TOTAL (D+E) & $17.047,78$ & $16.282,62$ & $16.423,55$ & $-4,49$ \\
\hline
\end{tabular}

Fonte: Dados da Pesquisa, 2011.

O Cenário 1 corresponde ao grupo controle. Nele, não houve despesas com os testes OGM e armazenagem segregada, os fluxos comerciais ocorreram somente com base nos custos de transporte. Esse cenário representa as transações comerciais sem a imposição do PCB. Com o foco de analisar os impactos no âmbito do PCB através do artigo 18.2.a e 
considerando o uso do termo "contém”, os custos dos testes de segregação foram incorridos no Cenário 2.

No Cenário 2, o sistema de identificação e quantificação de eventos transgênicos do milho gerou um impacto negativo de 4,49\% na comercialização. Os fluxos internacionais foram os mais atingidos, com perdas de 765 mil de toneladas. As exportações destinadas para o Irã e para a Taiwan, que são os principais parceiros do Brasil, reduziram-se em 10,0\% e $5,64 \%$, respectivamente.

As reduções comerciais mais significativas ocorreram nas regiões brasileiras mais distantes dos portos de exportação, em que os aumentos de custos que impactam a rede logística são mais fortemente percebidas. As principais quedas foram no Estado do Mato Grosso do Sul (Região Centro-oeste do Brasil) 5,79\%, seguido pelo Norte do Estado do Paraná (Região Sul do Brasil) 5,74\% e Norte do Estado do Mato Grosso (Região Centro-oeste do Brasil) 5,22\%.

O Cenário 2 dá indícios da perda de competitividade do milho brasileiro e, ainda, dos impactos regionais. Através dos parâmetros fornecidos, é possível identificar como o desempenho produtivo e o consumo nas regiões analisadas modificam-se quando um acordo internacional é simulado. Para escoar a produção brasileira é preciso realizar um maior número de transbordos, dadas as longas distâncias aos portos exportadores, já os principais concorrentes - Estados Unidos e Argentina - detêm uma maior eficiência logística, assim a redução competitividade do Brasil torna-se iminente.

Com relação às perdas monetárias, considerando as despesas com os testes e armazenagem (US\$506 milhões) e a redução do comércio internacional (US\$212 milhões), as perdas atingem US\$718 milhões. Este montante representa 27,4\% das divisas geradas pelas exportações de milho grão pelo Brasil em 2011, que totalizaram, segundo dados do Ministério do Desenvolvimento da Indústria e Comércio Exterior (MDIC), US\$2,62 bilhões.

A partir da simulação dos Cenários 2 é possível verificar que os desencadeamentos do PCB terão reflexos diferenciados nas principais regiões produtoras brasileiras. As perdas neste cenário oscilaram entre $0,64 \%$ a $5,79 \%$. Os Quadros 1 e 2 apresentam os fluxos comerciais e as rotas logísticas utilizadas para a movimentação da soja nos Cenários 1 e 2, respectivamente.

Quadro 1. Fluxos comerciais por rota de transporte, Cenário 1 (mil toneladas).

\begin{tabular}{|c|c|c|c|c|c|c|c|c|}
\hline \multirow{2}{*}{ Oferta } & \multirow{2}{*}{ Demanda } & \multicolumn{7}{|c|}{ Rota } \\
\hline & & R1 & $R 2$ & $R 3$ & $R 8$ & $R 10$ & $R 14$ & R15 \\
\hline PR-O & SC & & $1.001,27$ & & & & & \\
\hline PR-O & SP & 288,57 & & & & & & \\
\hline PR-O & RS & & & 130,76 & & & & \\
\hline MS & SC & & $1.962,46$ & & & & & \\
\hline MG & SC & & 215,66 & & & & & \\
\hline PR-N & Irã & & & & & $2.840,98$ & & \\
\hline PR-O & Japão & & & & & 31,84 & & \\
\hline MT-N & \begin{tabular}{|l|} 
Taiwan \\
\end{tabular} & & & & & & & $3.826,99$ \\
\hline MT-SE & Taiwan & & & & 276,11 & & & \\
\hline MT-SE & Japão & & & & 981,16 & & & \\
\hline MG & Irã & & & & & & $2.488,67$ & \\
\hline GO & Japão & & & & $3.003,32$ & & & \\
\hline
\end{tabular}

Cenário 1: não houve despesas com testes para detecção de OVMs.

Rota rodoviária (unimodal): R1; R2; R3; Rota intermodal: R8; R10; R14; R15.

Fonte: Dados da pesquisa, 2011.

No Cenário 1, uma parcela da produção de milho de Minas Gerais (MG) foi destinada ao mercado doméstico, abastecendo Santa Catarina (SC) na Região Sul do Brasil, utilizando apenas o transporte rodoviário (rota R2). Outra parcela da produção foi direcionada para o Irã, sendo exportada através do porto de Vitória (ES). Para esse fluxo, as vias rodoviárias e ferroviárias foram utilizadas (rota intermodal). O milho foi transportado por caminhões até o 
terminal ferroviário localizado na cidade de Araguari (MG, e de lá foi, transportado, por via férrea, até o porto de Vitória (rota R14).

A movimentação do milho dessa região no Cenário 2, em que houve um aumento dos custos logísticos pela imposição do PCB, modificou-se. A região passou a fornecer um volume maior aos mercados locais e passou a exportar milho para Taiwan. Além dessa modificação, o percurso para o mercado internacional mudou (a rota intermodal (R14) antes utilizada no Cenário 1 deixou de ser competitiva). A exportação foi feita pelo porto de Santos via rodoviário (rota $\mathrm{R} 4)$.

Quadro 2. Fluxos comerciais por rota de transporte, Cenário 2 (mil toneladas).

\begin{tabular}{|c|c|c|c|c|c|c|c|}
\hline \multirow{2}{*}{ Oferta } & \multirow{2}{*}{ Demanda } & \multicolumn{6}{|c|}{ Rota } \\
\hline & & $R 1$ & $R 2$ & R3 & R4 & R9 & R15 \\
\hline PR-O & RS & & & 130,94 & & & \\
\hline MS & SP & 289,11 & & & & & \\
\hline MS & SC & & $1.559,81$ & & & & \\
\hline MG & SC & & $1.650,91$ & & & & \\
\hline PR-N & Irã & & & & & $2.677,80$ & \\
\hline PR-O & Irã & & & & & $1.312,28$ & \\
\hline MT-N & Japão & & & & & & $3.627,04$ \\
\hline MT-SE & Irã & & & & 806,82 & & \\
\hline MT-SE & Taiwan & & & & 392,35 & & \\
\hline MG & Taiwan & & & & 959,70 & & \\
\hline GO & Taiwan & & & & $2.519,56$ & & \\
\hline GO & Japão & & & & 356,29 & & \\
\hline
\end{tabular}

Cenário 2: incluem custos dos testes para 1 evento e segregação. Tarifa ad-valorem: rotas rodoviárias: 55\%; rotas intermodais: $60 \%$.

Rota rodoviária (unimodal): R1; R2; R3; R4;R9. Rota intermodal: R15.

Fonte: Dados da pesquisa, 2011.

Outra análise que pode ser feita diz respeito às rotas utilizadas. No Cenário 1 , as exportações eram feitas via opções intermodais, responsáveis por $100 \%$ das movimentações (13,45 milhões de toneladas). Já no Cenário 2, apenas 29\% do milho com destino ao mercado internacional se deram por opções intermodais (aproximadamente 3,6 milhões de toneladas. Apenas as exportações da região Norte do Mato Grosso utilizaram a intermodalidade como opção competitiva. A implementação de medidas de segregação fizeram com que $71 \%$ das rotas intermodais deixassem de ser competitivas em função do aumento do custo, e o modal rodoviário foi priorizado e sobrecarregado. Ou seja, os custos de implementação do PCB tiveram um impacto maior nas rotas intermodais devido ao maior número de testes requeridos e ao aumento da demanda por armazenagem segregada, esses fatores contribuíram para o aumento do custo de transporte em relação às rotas unimodais que utilizam apenas o modal rodoviário para a movimentação do milho.

\section{CONSIDERAÇÕES FINAIS}

Os avanços do agronegócio brasileiro podem ser explicados pelo sucesso da combinação de fatores que vão desde cadeias produtivas mais integradas, pelo uso intensivo de capital nos diversos segmentos que o compõe e os programas governamentais de apoio à agricultura. Por outro lado, o setor logístico não tem atingido mesmo nível de desenvolvimento e tem revelado diversas fragilidades, seja pela falta de infraestrutura para escoar a produção, seja pela incapacidade de armazenar de forma adequada a safra nacional.

A logística de transporte e armazenagem, que até o momento tenta se adequar à movimentação de produtos padronizados e em grandes volumes, deverá se adaptar rapidamente para dar conta da crescente demanda por produtos diferenciados, que precisam ser segregados e exigirão adaptações no atual sistema logístico. 
A partir do modelo proposto verificou-se que os fluxos comerciais exigiram a realização de testes ao longo da cadeia, o que se refletiu em uma diminuição da competitividade do milho brasileiro. O efeito é maior nos Estados de fronteira, como Mato Grosso, assim, a exigência de segregação pode interferir nas decisões de produção dos agricultores apenas para atender a critérios que não são necessários do ponto de vista da biossegurança. De certa forma, o PCB também impõe um aumento no custo de oportunidade em se adotar uma nova tecnologia.

Do ponto de vista da competitividade, a implementação de Sistemas de Preservação de Identidade que levem a um aumento nos custos fixos, sem conexão direta com o cumprimento dos objetivos do Protocolo, poderá bloquear o acesso do agricultor à tecnologia, o que é feito facilmente pela compra de sementes. Também impede que a concorrência entre as empresas do mercado de sementes híbridas se exerça de forma plena, ao atrasar as liberações de cultivares resistentes a insetos e ao limitar o leque de ofertas para escolha pelos agricultores, sob o argumento falso de que pequenos agricultores preferem variedades locais e não híbridas.

Dessa forma, o que se verifica é um conflito entre importadores e exportadores de commodities agrícolas. De um lado os esforços dos países importadores em estabelecer um sistema extremamente exigente em nome da biossegurança. Por outro lado, os grandes exportadores de OVMs preocupados com os custos de implementação do Protocolo e com a possibilidade da criação de novas restrições ao comércio internacional. Uma importante contribuição para tentar equacionar esses desvios é a implementação de contratos bilaterais e/ou previsão de mecanismos para a redução de tarifas impostas pelos países importadores, na tentativa de reduzir os impactos negativos do PCB.

$\mathrm{Na}$ atualidade, o Brasil enfrenta o desafio de reduzir seu déficit na capacidade de armazenamento e transporte, um processo baseado no aumento da eficiência operacional e, ainda, tirando vantagem das economias de escala e escopo. A imposição de Sistemas de Preservação de Identidade em larga escala não só significaria desviar os recursos necessários do agronegócio para acompanhar a taxa de crescimento do Brasil, mas também criaria incertezas quanto ao tipo de investimento que deve ser feito.

De qualquer maneira, é fundamental as discussões quanto à regulação dos OGMs vislumbrem os investimentos em infraestrutura, para que a própria biotecnologia agrícola mostre seus efeitos positivos ao consumidor e aos países cujo talento se manifesta na competitividade do agronegócio.

\section{REFERÊNCIAS BIBLIOGRÁFICAS}

[1] ALVIM, A. M. Os impactos dos novos acordos de livre comércio sobre o mercado de arroz no Brasil: um modelo de alocação espacial e temporal, 221 p. 2003. Tese (Doutorado em Economia) - Universidade Federal do Rio Grande do Sul, Porto Alegre. 2003.

[2] ALVIM, A. M.; Waquil, P. D. O problema de complementaridade mista: um modelo de alocação espacial aplicado ao setor agrícola. In: Santos, M. L.; Vieira, W. C. Métodos quantitativos em economia. Viçosa: UFV, p. 161 - 190, 2004.

[3] ANTT: Agência Nacional de Transportes Terrestres. Relatório Anual 2006. Disponível em:<http://www.antt.gov.br/default.asp>. Acesso em: jan. 2010.

[4] BISHOP, P.M.; NICHOLSON, C.F.; PRATT, J.E. Tariff-Rate Quotas: difficult to model or plain simple. Wellington: NZIER, 2001. In: Conference of the New Zealand Agricultural and Resource Economics Society. Disponível em: http://www.nzier.co.nz. Acesso: 01/Mai/2006

[5] BOÜET, A.; GRUÈRE, G.; LEROY, L. From “May Contain” to "Does Contain”: The price and trade effects of strict information requirements for GM maize under the Cartagena Protocol on Biosafety. CAES \& WAEA Joint Annual Meeting, Agricultural \& Applied 
Economics Association's, Denver. Anais CAES \& WAEA Joint Annual Meeting, Agricultural \& Applied Economics Association's, 26p, 2010.

[6] BRANCO, J. E. H.; CAIXETA FILHO, J. V. Principais gargalos para a movimentação de produtos agrícolas diferenciados no Brasil. Revista Grãos Brasil: da semente ao consumo, Maringá, n. 17, p. 28-34, 2004.

[7] BRASIL. Ministério da Agricultura, Pecuária e Abastecimento. Agrostat. Estatísticas de Comercio Exterior do Agronegócio Brasileiro. Disponível em: <http://sistemasweb.agricultura.gov.br/pages/AGROSTAT.html>. Acesso em: mar. 2014.

[8] BRASIL. Conab. Companhia Nacional de Abastecimento. Previsão de Safra. Disponível em: < http://www.conab.gov.br/conteudos.php?a=1028\&t=2>. Acesso em: jan. 2014.

[9] BROOKE, A.; KENDRICK, D.; MEERRAUS, A. GAMS: a user's guide. Release 2.25. Redwood: The Scientific Press. 289 p. 1995.

[10] CAIXETA FILHO, J. V. Especificidade das modalidades de transporte para a movimentação de produtos agrícolas. In: CAIXETA- FILHO, J. V.; GAMEIRO, A. H. (Org.). Transporte e Logística em Sistemas Agroindustriais. São Paulo, SP: Atlas, 218p, 2001.

[11] CAIXETA FILHO, J. V. Logística para a agricultura brasileira. Revista Brasileira de Comércio Exterior, n. 103, Abril/Junho 2010, p. 18-30, 2010.

[12] CAVALCANTE, J.; MERCENIER, J. Uma avaliação dos ganhos dinâmicos do Mercosul usando equilíbrio geral. Pesquisa e Planejamento Econômico, v.29, n.2, 1999.

[13] CEPEA. Centro de Estudos Avançados em Economia Aplicada. PIB do Agronegócio. Disponível em: <http://cepea.esalq.usp.br/pib/>. Acesso em: mar. 2014.

[14] FAPRI. Food and Agricultural Policy Research Institute. Elasticities Database. 2011. Disponível em: <http://www.fapri.org/tools/elasticity.aspx>. Acesso em: abr. 2012.

[15] FULLER, S. et al. Effect of Improving South American Transportation System on U.S. and Soutth American Corn and Soybean Economies. Washington: USDA, 40p. 2001. Disponível em: $<$ http://afcerc.tamu.edu/publications/PublicationPDFs/IM\%2002\%2001\%20south\%20america\%20pub.pdf>. Acesso em: nov. 2002.

[16] FULLER, S. et al. Transportation developments in South America and their effect on international agricultural competitiveness. Journal of the Transportation Research Board, Washington, issue 1820, p.62-88, 2003.

[17] IBGE. Instituto Brasileiro de Geografia e Estatística. Contas Nacionais. Disponível em:<http://www.ibge.gov.br/home/estatistica/indicadores/pib/defaultcnt.shtm>. Acesso em: mar.2014.

[18] JAMES, C. Global status of commercialized biotech/GM crops: 2013. ISAAA Brief issue 43. ISAAA: Ithaca, NY, 2013.

[19] MACKENZIE, R. et al. An explanatory guide to the Cartagena Protocol on Biosafety. Gland, Switzerland and Cambridge: IUCN, 295 p., 2003. Disponível em: $<$ http://www.agricultura.gov.br/internacional/indicadores-e-estatisticas/balanca-comercial $>$. Acesso em: set. 2012.

[20] McCARL, B. A., SPREen, T. H. Applied Mathematical Programming Using Algebraic Systems. College Stations: Texas A\&M University (mimeo), 2001.

[21] OLIVEIRA, A. L. R.; SILVEIRA, J. M. F. J.; ALVIM, A. M. Cartagena protocol, biosafety and grain segregation: the effects on the soybean logistics in Brazil. E3 Journal of Agricultural research and development, v. 2, p. 17-30, 2012.

[22] RUTHEFORD, T.F. Extension of GAMS for complementarity problems arising in applied economic analysis. Journal of Economics Dynamics \& Control, v. 19, p. 1299-1324, 1995. 
[23] SAFRAS \& Mercado. Banco de Dados - Milho 2011. Disponível em:<http://www.safras.com.br/>. Acesso em: set. 2012.

[24] SAMUELSON, P.A. Spatial Price Equilibrium and Linear Program. American Economic Review, v.42, p.283-303, 1952.

[25] SCHLECHT S. M.; WILSON, W.W.; DAHL, B. L. Logistical Costs and Strategies for Wheat Segregation. Agribusiness \& Applied Economics Report, n. 551, Fargo: North Dakota State University, 41 p., 2004.

[26] SIFRECA. Sistema de Informações de Fretes. Fretes Rodoviários e Ferroviários - Milho 2011. Disponível em: http://sifreca.esalq.usp.br/sifreca/pt/index.php. Acesso em: abr. 2012.

[27] SILVEIRA, J. M. F. J. Inovação tecnológica na agricultura, o papel da biotecnologia agrícola e a emergência de mercados regulados. In: GASQUES, J. G.; VIEIRA FILHO, J. E. R.; NAVARRO, Z. (Org.). A Agricultura Brasileira: desempenho, desafios e perspectivas. Brasília: Ipea, 298 p., 2010.

[28] TAKAYAmA, T.; JUDGE, G.G. Spatial and Temporal Price and Allocation Models. Amsterdam: North Holland Publishing Co., 1971.

[29] THOMPSON, R.A. Survey of Recent U.S. Developments in International Agricultural Trade Models. Washington, D.C.: USDA/ERS, 1981.

[30] THORE, S. Economic logistics: the optmization of spatial and sectoral resource, production and distribution systems. New York: Westport: London: Quorum Books, 1992.

[31] USDA. United States Departament of Agriculture. Production, Supply and Distribution Database. Disponível em: <http://www.fas.usda.gov/psdonline/psdHome.aspx>. Acesso em: mar. 2014.

[32] WAQUIL, P.D.; COX, T.L. Spatial Equilibrium with Intermediate Products: Implementation and Validation in the MERCOSUL. Agricultural Economics, Staff Paper Series, n. 388. 1995. Disponível em: <http://www.aae.wisc.edu/www/pub/sps/stpap388.pdf>. Acesso em: 01/Ago/2003.

[33] YAVUZ, F. et al. A Spatial Equilibrium Analysis of Regional Structural Change in the U. S. Dairy Industry. Review of Agricultural Economics, Lexington, vol. 18, p. 693-703, 1996. 